NOTICE: this is the author's version of a work that was accepted for publication in Transportation Research Part D: Transport and Environment. Changes resulting from the publishing process, such as peer review, editing, corrections, structural formatting, and other quality control mechanisms may not be reflected in this document. Changes may have been made to this work since it was submitted for publication. A definitive version was subsequently published in Transportation Research Part D: Transport and Environment, Volume 23, August, 2013, Pages 20-24, http://doi.org/10.1016/j.trd.2013.03.011 


\title{
Urban Transportation in Chinese Cities: \\ An Efficiency Assessment
}

\begin{abstract}
We use 2008 statistical data for 34 Chinese cities to analyze and compare urban transportation using super-efficiency Data Envelopment Analysis (SE-DEA). The results indicate contrasting regional differences, with economically stronger eastern and central cities focusing more on high capacity and less on sustainable modes of transportation, while western cities experiencing the contrary. The Tobit model analysis shows that the Chinese cities with more sustainable transportation are also more likely to have lower gross domestic product per capita, smaller city size, lower urbanization level and higher bus usage. Hence, the existing model of urban development as far as transportation is concerned, challenges China's recent ambitions to achieve an environmentally-friendly society.
\end{abstract}

Keywords: Urban Transportation; Sustainability; Cities; Super-efficiency DEA; Affecting Factors 


\section{Introduction}

China is becoming a more car-dependent society and this has been radically demonstrated since the beginning of the $21^{\text {st }}$ century with the number of vehicles on its roads significantly increasing and its major cities starting to sprawl. In 2011, civilian car ownership reached nearly 106 million, including more than 78 million private cars; compared to the previous year, the ownership of civilian cars increased by $16.4 \%$ and of private cars by 20.4\% (National Bureau of Statistics of China, 2011). Fast urbanization and the growing number of people flowing towards the cities are contributing to urban sprawl and increasing the number of vehicles on the road. Traffic related air pollution, accidents and congestion are becoming progressively serious problems.

In the past, the emphasis of transportation plans in China has been on increasing traffic capacity. However, the 12th Five-Year Plan Guideline for Transportation brings a new focal point, namely the achieving of a resource-saving and environment-friendly society. Sustainable development, or proper integration of economic, environmental and social priorities, has attracted the Chinese government's attention since the 1980s but only recently it became a policy priority, referred to as the building of a dual-goal society (Jia et al., 2010; Jia et al., 2013).

Transportation is an important aspect of the sustainable transformation process for any economy. The European Conference of Ministers of Transport (2004) states that a sustainable transport system should be affordable, accessible, safe and environmentally friendly. Similarly, the Canadian Center for Sustainable Transportation (2005:5-6) defines a sustainable transport system as one that: (a) allows the basic access needs of individuals and societies to be met safely and in a manner consistent with human and ecosystem health, and with equity within and between generations; (b) is affordable, operates efficiently, offers choice of transport mode, and supports a vibrant economy; and (c) limits emissions and waste within the planet's capacity to absorb them, minimizes consumption of non-renewable resources, limits consumption of renewable resources to the sustainable yield level, reuses and recycles its components, and minimizes the use of land and the production of noise. Despite this being considered the 
best definition of a sustainable transport system (e.g. Litman, 2007; Yevdokimov and Han, 2004), the priorities of China's dual-goal society stress only the two aspects of resource efficiency and reduced environmental impact (Ministry of Transport of People’s Republic of China, 2011).

The aim of this paper is to analyze transportation in Chinese cities from the point of view of the dual-goal society. We explore these issues by evaluating the sustainability of urban transport in 34 large and medium cities in China's eastern, central and western provinces. There are vast differences in the level of urbanization and transportation development across the country. The evaluation is based on indicators drawn from Jeon and Amekudzi (2005) who classified the measures of sustainable transportation into the four categories of transportation, environment, economy and society. A composite index named efficiency value, which represents the sustainability of the urban transport in each city, is calculated by adopting the super-efficiency Data Envelopment Analysis (DEA) model. The 34 cities are then ranked according to their efficiency values. We also simultaneously calculate an efficiency value for the transportation systems based on the traditional thinking of transport capacity. Using the Tobit model, this allows us to compare the two types of efficiency values and examine the determinants of urban transport sustainability in China.

More information about the methodology and data used in this study is presented in Section 2. Section 3 describes the results from the analysis and Section 4 generates the sustainability determinants in the case of the Chinese cities sample. The last section provides concluding remarks and outlines policy recommendations.

\section{Methodology and data}

Chinese urban transportation is evaluated using the super-efficiency DEA model (Andersen and Petersen, 1993) in order to determine, differentiate, compare and rank the relative efficiency of its Decision Making Units (DMUs). The set of 34 cities (the full list of cities is shown in Tables 1 and 2), which are assumed to be the DMUs, consists of 25 provincial capital cities, 4 centrally administered municipalities (Beijing, 
Chongqing, Shanghai and Tianjin) and 5 additional major cities (Dalian, Ningbo, Qingdao, Shenzhen and Xiamen). Cities in the provinces of Taiwan, Hong Kong, Macau, Tibet and Ningxia are excluded because of unavailability of data. The latest available complete data used in the analysis is for 2008 and has been obtained from the Urban Construction Statistical Yearbook (National Bureau of Statistics of China, 2009a), China Statistical Yearbook (National Bureau of Statistics of China, 2009b) and Urban Statistical Yearbook (Ministry of Housing and Urban-Rural Development of China, 2009).

The input and output indicators for the 34 DMUs are set up based on the principle of data envelopment analysis while taking into consideration the dual-goal society. We calculate two types of efficiency values: (1) efficiency value which indicates the sustainability level of urban transportation, and (2) efficiency value which represents the capability of urban transportation. Sustainability and capability represent different aspects of the urban transport system, therefore two categories of index frameworks are set up; they have the same input but different output indicators.

\subsection{Input indicators}

According to the resource-saving aspect of China's dual-goal society, a sustainable transportation development mode should emphasize efficient use of natural resources. Resource use is similarly a major aspect of capacity building in transportation. Hence required resources for urban transport are inputs for both index frameworks and DEA models. Input indicators are selected from the areas of land use, transport facilities, fixed investment and human resources.

Land use. China's population growth and rapid urbanization lead towards increased land use in the cities (Lu, 2012). Urban transport in particular requires roads and parking spaces to meet the travel demands of residents. As a more convenient transportation tends to encourage people to travel more, a growing portion of urban land is being dedicated to transport facilities (Litman, 2001). Land area occupied by road- and railways (in ten thousand square meters) is selected to represent the urban land use of transportation. 
Transport facilities. Existing transport facilities are the main resources of the urban transportation system. The two indicators chosen from the 16 listed by Jeon and Amekudzi (2005) are length of roads (in kilometers) and motor vehicles (total number of vehicles). They are selected to represent the state of transport facilities in Chinese cities.

Fixed investment. In addition to the fixed infrastructure and existing facilities, investment from local government on an annual basis is essential to continuously support and promote the development of urban transport. Total investment in public transport (in ten thousand Chinese Yuan, CNY) is adopted to reflect this input indicator.

Human resources. Every industry needs human resources and transportation is not an exception. Employment in transport (in million people) is used to represent investment in human capital.

\subsection{Output indicators}

There are two sets of output indicators, one applicable for the sustainability efficiency value and the other for the capacity efficiency value.

\section{Output indicators - sustainability}

The environmental friendliness objective of China's dual-goal society requires production and consumption activities to occur in accordance with the ecological carrying capacity. In order to be sustainable, transport development should be decoupled from environmental pollution; however this has not been the case and urban transportation has had significant negative environmental impacts, including air pollution, threatening people's health. Several indexes are used to reflect the impact of transport and they are regarded as the environmental outputs of urban transportation. The United States Environmental Protection Agency (1999) points out that the most recognized environmental implications of transportation is the effect of motor vehicles on air quality. Together with air pollution, previous research also highlights noise as the most common consequences and environmental costs of road transport (Verhoef, 1994). Hence we use air pollution and noise level of traffic as the environmental output 
indicators.

Emissions of air pollutants. At present, the main source of urban air pollutants in China is automobile exhaust (MEP, 2010). It contains various harmful substances, such as $\mathrm{CO}$, nitrogen oxides and hydrocarbons among others. Based on the abundant evidence of the harmful effects of nitrogen dioxide $\left(\mathrm{NO}_{2}\right)$ on human health (e.g. Hoek et al., 2002), we have opted to adopt annual daily average $\mathrm{NO}_{2}$ (in milligram per cubic meter) as the traffic air pollution index.

Noise level. Exposure to noise constitutes a health risk (WHO, 2013). It is widely accepted that a high noise emission level in daytime may be detrimental to people (European Economic Area, 2001). We represent the noise level by using as an indicator the equivalent sound level of road traffic noise (in decibels).

\section{Output indicators - capacity}

From a mainstream development perspective, urban transportation is a major contributor to the economy. The traffic outputs used here cover transportation capacity and economic development.

Transportation capacity. It is understandable that the main task of urban transport is transiting passengers and freights. The indicators "passenger traffic" (in million people) and "cargo traffic" (in ten thousand tons) are used to assess transport's ability.

Economic development. It is difficult to separate economic development in the cities from transportation. It fuels economic growth by allowing accessibility to resources and markets (Rassafi and Vaziri, 2005). The indicator used to represent the importance of urban traffic for the economy is GDP generated by transport sector. Due to the unavailability of broken-down data, we use "transport, storage and postal industry GDP” (in one hundred million CNY) instead of “transport sector GDP”.

The results from the analysis based on the above indicators are presented below.

\section{Results and discussions}

Using the two DEA models, two efficiency values, namely SE1 (sustainability 
efficiency value) and SE2 (capacity efficiency value) were computed with MATLAB7.0 software. The respective DEA results, namely efficiency values and rankings, are presented in Tables 1 and 2. As the DEA method requires all data to be non-negative, the negative environmental output indicators, namely the annual daily average $\mathrm{NO}_{2}$ and equivalent sound level of road traffic noise, were adjusted before computing the SE1 efficiency.

<Table 1 about here>

$<$ Table 2 about here $>$

The results in Tables 1 and 2 show significant differences in transport efficiencies among the selected Chinese cities. This is not unexpected as China's coast (including the cities of Beijing, Tianjin, Shijiazhuang, Shenyang, Dalian, Shanghai, Nanjing, Hangzhou, Ningbo, Fuzhou, Xiamen, Jinan, Qingdao, Guangzhou, Shenzhen and Haikou) and central areas (including the cities of Hohhot, Changchun, Harbin, Taiyuan, Hefei, Nanchang, Zhengzhou, Wuhan, Changsha and Nanning) are more economically developed than the western parts of the country (including the cities of Xining, Guiyang, Lanzhou, Urumqi, Xi'an and Chongqing). In terms of SE1, Xining has the highest value of 1.8994 and Shanghai has the lowest value of 0.0881 . The highest SE2 value is 2.2638 for Hohhot and the lowest is 0.3802 for Beijing. The country’s capital Beijing appears to not only have the worst transport efficiencies ranking at the bottom for sustainability but is also second last for capacity efficiency. At the other end of the spectrum, Hohhot is the best performing city in terms of transport sustainability and second best in capacity efficiency.

As transportation in Chinese cities is managed by their regional governments, the policies and measures affecting urban transport vary substantially. This leads to inconsistencies and dissimilarities in the input on resources as well as in the choice of travel modes. It also explains the vast regional and national differences in transport efficiencies across cities.

Notwithstanding the individual discrepancies, the SE1 average values for the 
eastern, central and western cities (0.36, 0.56 and 0.71 respectively) indicate a negative link between economic development and sustainability transport efficiency - the more economically developed areas are likely to have lower environmental efficiency of urban transport. In other words, transportation in the more developed cities generates higher levels of pollution and noise. If China's central and eastern regions were to achieve sustainability transport efficiency similar to that of the west, they would need to reduce their current environmental outputs by $15 \%$ and $35 \%$ respectively.

On the contrary, the SE2 average values for the eastern, central and western cities (0.88, 0.92 and 0.79 respectively) indicate that the west has less transport capacity efficiency than the central and eastern regions which may stem from the diverse speeds and degrees of urbanization. Because city size and urban population are expanding quickly in eastern and central China, the demand for urban transport in these cities is also increasing. The western cities on the other hand are not as prosperous and are still at the early stage of the urbanization process. Hence the economic functions of transport in the eastern and central cities are more prominent than in the cities in the west.

The SE2 efficiency values are higher than SE1 values for the majority of Chinese cities (the only exceptions are Lanzhou, Changchun, Xining and Xiamen). In other words, as far as transport is concerned the Chinese cities are achieving better capacity than sustainability efficiency. This is in line with the Environmental Kuznets Curve (EKC) which suggests that a lot of resources are required in the take-off stage of economic development and if the rate of resource use exceeds the speed of their regeneration, this can trigger environmental degradation (Grossman and Krueger, 1991). Only when a particular level of wealth is achieved, can the environment become an area of consideration with optimized economic structures and new technologies required to reduce or eliminate environmental degradation. It appears that China is still on the initial development path that causes environmental deterioration and improved transportation in Chinese cities comes at the cost of the healthy urban environment. The eastern region shows greater disparity between SE2 and SE1 (with a difference of 0.52). Job opportunities in these cities are attracting a lot of new people moving from the 
central and western parts of the country and they put additional demand on urban transportation. Population movement in China is a major phenomenon with an estimated 173 million of floating workers (National Bureau of Statistics of China, 2009a) - people who do not live permanently in the cities but are present there for work. The surge in floating population further deteriorates the urban resources and environment through higher frequency of transport use and consequently more pollutant emissions and noise. This is highly evident in the eastern cities. Beijing in particular is being affected by such influx in people and its transport system is struggling not only environmentally but also in providing the needed capacity.

Furthermore, the SE-DEA model is used to evaluate the relative efficiency of the cities’ DMUs (or their regional governments). For this purpose, we use the reverse rankings for both SE1 (R1') and SE2 (R2'), i.e. in ascending order (in other words, a city ranks higher if its rank is higher). This is presented in Figure 1. Cities with R2' larger than R1' are those which have a more developed economy and are relatively larger. This group includes Shanghai, Guangzhou, Chongqing, Tianjin, Wuhan and Qingdao among others. On the other hand, cities with R1' larger than R2' are mostly small or medium-sized. This group includes Xining, Lanzhou and Guiyang among others. Finally, there is the group of cities whose both ranks are very similar. This means that their DMUs are paying equal attention to transport sustainability and capacity efficiency. Hohhot and Beijing are two prominent examples of this but while Hohhot (with a population of around 2 million) is placed at the start of the scale, Beijing (with a population of around 22 million) is located last. Consequently Hohhot has the best efficiencies and the most balanced approach while Beijing seems to be the worst example.

$<$ Fig.1 about here $>$

\section{Factor analysis}

There are many factors affecting the sustainable transport efficiency, including urban transport policy, travel mode, urbanization level, economic development level, 
urban scale and so on. This section defines indicators to reflect these factors and uses the Tobit model to further validate the relationship between the factors and the SE1 value.

Public transport is an essential, in many cases primary, transportation mode in a city. Currently, many cities have realized that giving priority to the development of public transport systems can effectively relieve urban traffic pressure and reduce environmental emissions (Newman and Kenworthy, 1999). An advanced public transport will significantly enhance the environmental efficiency of urban transportation. While railway networks are still limited only to the large Chinese cities, bus transport remains the prevailing mode of urban public transport. Hence we use number of buses per million people (vehicles) to represent the government investment in public transport. It is however unclear whether high public transportation can reduce environmental output, hence the correlation between this indicator and the SE1 value is indeterminate.

Furthermore we use the number of bus trips per million people (trips/million) to reflect the acceptance and popularity of public transport as a mode of transportation. We expect that there is a positive correlation between this indicator and SE1. The scale effect of the EKC theory implies that a fast developing economy would have a negative effect on the environment in its early stages. Hence we use per capita GDP (in CNY) to indicate the economic development.

According to Zhang et al. (2010), modern cities are characterized by large disparities in the level of urbanization. Large cities grow rapidly while the number of small cities declines. The increasing level of urbanization and the expanding city size will inevitably stimulate potential requirements for developing urban transport. To meet the demands of the aggregating urban population and expanding economy, China's urban transport is developing radically with cities building highways and viaducts. More and more cities are also implementing rail transport. However, China's urban transport is only focused on travel convenience. Although environmental issues may be mentioned, they are not included as a target. High urbanization level and large urban scale may lead to negative effects on SE1. We use the proportion of urban 
metropolitan residents in total city population ${ }^{1}$ (as a \%) to reflect the urbanization level, and total population (million people) to represent urban size.

Since the range of the efficiency value of the super-efficiency DEA model is $(0, \infty)$, the dependent variables in the regression equation are limited. Parameter estimation will result in serious bias and inconsistency if the least-squares method is used. The Tobit model is a better alternative. It is a limited dependent variable method which is used with the value of the dependent variable truncated or censored. We set the affecting factors as the independent variables of the Tobit model and conduct a regression analysis using Stata12.0 software. The regression results are provided in Table 3, in which models I and II show the coefficient estimates of the explanatory variables and significance levels. Model II is constructed to conduct a robustness test, in which we set the variable $a 1$ ' to represent the public transport investment of each city, and set a regional dummy variable $a 3^{\prime}$ to measure the economic level of development. If a city has rail transport, the value of its $a 1^{\prime}$ is 1 , otherwise $a 1^{\prime}$ is 0 . If a city is in the east of China, $a 3^{\prime}=1$, otherwise $a 3^{\prime}=0$. The robustness test of model II shows that the role of all variables does not change direction and they have the same significance level as in model I. This indicates that the result with model I are robust.

$<$ Table 3 about here $>$

Table 3 shows that most explanatory variables test significantly except of the variable $a 1$ or $a 1$, and that the correlation is consistent with the expectation. The significant negative correlation relationship between the level of economic development and efficiency value SE1 demonstrates that China's urban transport is indeed in its infancy according to the EKC theory. Furthermore, as it appears that China is still positioned at the beginning of the raising slope of the inverted U-shaped EKC, environmental quality is expected to continue to fall as income level rises. In order to avoid further deterioration, China's urban transport development should be focused on innovation and technology investment. The country needs to continuously develop and

\footnotetext{
${ }^{1}$ Chinese cities still include large rural areas.
} 
implement clean technologies while focusing on reforming the structure of its transportation resources. These can have technical and composition effects on China's EKC by reducing pollution and improving the environmental quality related to urban transport.

The results from the regression analysis also demonstrate that the level of urbanization and city size are significantly and negatively correlated with SE1, which may be caused by the negligence and lack of attention towards environmental emissions during the process of urbanization. This is consistent with the facts that PM2.5 and ozone pollution are increasing causing decreasing visibility and haze occurring frequently in Beijing, Tianjin, Hebei and other economically developed regions. The Ministry of Environmental Protection of China has issued exposure drafts to include PM2.5 and ozone concentrations into routine air quality assessment (MEP, 2012). The seriousness of the environmental emission problem associated with urban traffic has attracted government's attention but much more needs to be achieved.

Furthermore, the number of bus trips is positively correlated with SE1, which confirms that an environment-friendly choice for people, such as traveling by public transport, can indeed reduce environmental emissions associated with traffic, thereby enhancing the urban transport sustainability efficiency value. The fact that the indicators $a 1$ or $a 1^{\prime}$ are not significant further illustrates that if the government merely increases transport infrastructure investments, it would still be unable to reduce environmental emissions or improve the urban transport efficiency without encouraging people to change the way they travel in the city.

The mainland cities of China can learn from Hong Kong's experience of giving priority to developing a good public transport system. For example, Hong Kong chose to develop a reliable bus system before private cars entered the city's households. Constructing massive public transportation and road system has never been part of Hong Kong's transport policy. Instead, a variety of public transportation services compete and cooperate with each other, making Hong Kong residents feel that it is more convenient to travel by public transport than it is by private vehicles. 


\section{Conclusions and recommendations}

Using a sample of 34 cities in China, this paper presented the estimate results of a quantitative study measuring transport efficiencies related to sustainability (SE1) and capacity (SE2). The study found big differences between the SE1 and SE2 values for the Chinese cities indicating strong regional variations. The eastern and central regions show a transport development mode with low SE1 and high SE2, whereas the opposite is true for the western region of the contrary. One explanation is that investments in urban traffic resources in the western cities (which tend to be smaller) are lower than in the eastern and western metropolises as their economies lag and there is insufficient demand. Hence the negative effects of the economy on the environment have not yet manifested in the west. However the eastern and central cities are experiencing great changes in urbanization due to major social issues, such as expanding population, demand for public infrastructure construction and vigorous economies which make transport capacity take priority over sustainability.

It appears that improvement in transport performance and move towards sustainable transportation are to a certain extent mutually exclusive in China. The conflict between developing a transport system and an environment-friendly society has begun to emerge. At present, the cities with sustainable transportation tend to have lower per capita GDP, smaller city size, lower urbanization level and higher bus riding rates. Higher investment in public transport facilities does not significantly improve the level of sustainable transportation development.

By providing an assessment of urban transportation from a sustainability perspective, this study raises the issue about the conflict between the prevailing model of urban development and China's recent ambitions to achieve an environmentally-friendly society. As each Chinese city is relatively autonomous in selecting its strategies and transportation development path, policy makers should seriously examine the implications from the current trends and emphasize the need for a significant change. Achieving sustainability in the Chinese cities will not be different from any other global city where the potential offered by public transport can no longer be ignored. 


\section{Acknowledgements}

The first and second authors acknowledge the financial support from the National Natural Science Foundation of China (61004108, 91024027) and the large bid project from China's Social Sciences Fund (Project No. 08\&ZD043). The third and fourth authors acknowledge the financial support of the Australian Research Council. All authors are thankful to the Journal's Editor and its anonymous referees who provided useful feedback and helped improve the quality of the manuscript. 


\section{References}

Andersen, P., Petersen, N.C., 1993. A procedure for ranking efficient units in data envelopment analysis. Management Science 39, 1261-1264.

Centre for Sustainable Transportation, 2005. Definition Sustainable Transportation. Transport Canada, Ottawa. Available at http://cst.uwinnipeg.ca/completed.html (accessed August 23, 2012).

Ministry of Environmental Protection of People’s Republic of China (MEP), 2010. China Motor Vehicle Pollution Prevention Annual Report. Chinese Ministry of Environmental Protection, Beijing. Available at http://wfs.mep.gov.cn/dq/jdc/zh/201011/P020101110336607260005.pdf (accessed April 10, 2012)

Ministry of Environmental Protection of People’s Republic of China (MEP), 2010. Ambient Air Quality Standards. Chinese Ministry of Environmental Protection, Beijing. Available at http://kjs.mep.gov.cn/hjbhbz/bzwb/dqhjbh/dqhjzlbz/201203/t20120302_224165.htm (accessed 19 March 2013).

Ministry of Transport of People’s Republic of China, 2011. 12th Five-Year” Development Guideline of Transportation. Ministry of Transport, Beijing. Available at http://www.moc.gov.cn/zhuantizhuanlan/jiaotongguihua/shierwujiaotongyunshufazhanguihu a/jiaotongyunshushierwufazhanguihua_SRWJTFZGH/201106/t20110613_954154.html (accessed April 10, 2012).

European Conference of Ministers of Transport, 2004. Assessment and Decision Making for Sustainable Transport. European Conference of Ministers of Transportation and the OECD.

European Economic Area, 2001. Traffic noise: exposure and annoyance. European Environmental Agency, Copenhagen. Available at http://themes.eea.eu.int/Sectors_and_activities/transport/indicators/consequences/noise_expo sure/Noise_TERM_2001.doc.pdf (accessed April 10, 2012).

Grossman, G.M., Krueger, A.B., 1991. Environmental Impacts of a North American Free Trade Agreement. NBER Working Paper, No.3914. 
Hoek, G., Brunekreef, B., Goldboh, S, Fischer, P., van den Brandt, P.A. 2002. Association between mortality and indicators of traffic-related air pollution in the Netherlands: a cohort study. Lancet 360(9341):1203-1209.

Jeon, C.M., Amekudzi, A.A., 2005. Addressing Sustainability in Transportation Systems: Definitions, Indicators, and Metrics. Journal of Infrastructure Systems 11(1), 1076-0342.

Jia, R., Guo, X., Marinova, D., 2013. The Role of the Clean Development Mechanism in Achieving China’s Goal of a Resource Efficient and Environmentally Friendly Society. Environment, Development and Sustainability 15(1), 133-148.

Jia, R., Zhao, D.T., Guo, X., Marinova, D., 2010. Towards a Resource Efficient and Environmentally Friendly Society in China: Evaluation Method and Empirics, Transformations, 66-67(3-4): 208-226.

Litman, T., 2001. Transportation Cost Analysis for Sustainability. Victoria Transport Policy Institute, Victoria. Available at http://www.vtpi.org/sustain.pdf (accessed April 10, 2012).

Litman, T., 2007. Developing Indicators for Sustainable and Livable Transport Planning. Transportation Research Record: Journal of the Transportation Research Board 2017, 10-15. Lu, D., 2012. The Great Urbanization of China. World Scientific Publishing Co. Pte.Ltd, Singapore. Ministry of Housing and Urban-Rural Development of China, 2009. Urban Construction Statistics Yearbook. China Planning Press, Beijing.

National Bureau of Statistics of China, 2009a. Urban Statistical Yearbook. China Statistics Press, Beijing.

National Bureau of Statistics of China, 2009b. China Statistical Yearbook. Available from http://www.stats.gov.cn/english/statisticaldata/yearlydata/(accessed April 10, 2012).

National Bureau of Statistics of China, 2011. China’s Statistical Bulletin. Available from http://www.stats.gov.cn/tjgb/ndtjgb/qgndtjgb/t20120222_402786440.htm (accessed April 10, 2012).

Newman, P., Kenworthy, J. 1999. Sustainability and Cities: Overcoming Automobile Dependence. Island Press, Washington, DC.

Rassafi, A.A., Vaziri, M., 2005. Sustainable transport indicators: Definition and integration. International Journal of Environment Science and Technology 2(1), 83-96. 
United States Environmental Protection Agency, 1999. Indicators of the environmental impacts of transportation, 2nd. Ed., Washington, D.C. Available at http://www.epa.gov/otaq/transp/99indict.pdf (accessed April 10, 2012).

Verhoef, E., 1994. External Effects and Social Costs of Road Transport. Transportation Research Part A: Policy and Practice 28(4), 273-287.

World Health Organization. 2013. Noise. Available at http://www.euro.who.int/en/what-we-do/health-topics/environment-and-health/noise (accessed March 18, 2012).

Yevdokimov, Y., Han, M., 2004. A Systems Approach to Measuring Sustainability of Transportation. Proceedings of the International Conference on Transportation Systems Planning and Operation, pp519-528.

Zhang, W.C., Ma, Q.Y., 2010. Urban Transport and Urban Development. The Commercial Press, Beijing. 